\title{
Sequential leaching of copper from mill tailings with aqueous solutions of hydrochloric acid and sodium hypochlorite
}

\author{
Leilya Syzdykova ${ }^{1-}$, Nargiza Nurtazina $^{1}$, and Aidana Erdenbekova $^{1}$ \\ ${ }^{1}$ Al-Farabi Kazakh National University, department of Physical Chemistry, Catalysis and \\ Petrochemistry, 050040 Al-Farabi avenue 71, Almaty, Kazakhstan
}

\begin{abstract}
This work presents an investigation of kinetics of copper leaching from mill tailings with hydrochloric acid and sodium hypochlorite at room temperature in filtration mode. The concentration of hydrochloric acid and sodium hypochlorite varied from 0.05 to $0.5 \mathrm{M}$ and 0.025 to 0.1 $\mathrm{M}$ respectively. When the samples were leached in the sequence of fivehour leaching with solutions of hydrochloric acid, and then six-hour with sodium hypochlorite, the maximum degree of copper extraction into the solution was $32.62 \%$. And in case of leaching samples in the inverse direction, with a solution of sodium hypochlorite for two hours, and then with hydrochloric acid for seven hours, $87.10 \%$ of copper was extracted, which is 2.67 times more than in the previous case. It has been shown that the sequence of using reagents in leaching has a significant impact on the efficiency of copper extraction from the tailings.
\end{abstract}

\section{Introduction}

Ore and concentrates derived from them are processed by pyrometallurgical and hydrometallurgical methods. In global practice, $80 \%$ of non-ferrous metal concentrates can be processed pyrometallurgically. Hydrometallurgical methods in uncomplicated installations and at low temperatures can extract metals from oxidized, mixed and hard-toenrich ores, the composition of which is poor with non-ferrous metals containing approximately $1 \%$ of metal. In connection with this, interest in hydrometallurgical methods of obtaining non-ferrous metals from ores, concentrates and mill tailings remains stable [12]. The perspectives rapid development of the hydrometallurgical method of processing base ore is also due to the fact that in most cases it provides a high coefficient of raw materials using and the extraction of valuable components, requires less capital expenditure, and reduces environmental pollution with harmful substances compared to the pyrometallurgical method [3-4].

Leaching is the most important stage in the hydrometallurgical process, in which ore, concentrates, intermediates and waste of manufacturing are processed by aqueous-based solution of chemical reagents, followed by the release of metal from the solution and its compounds. The reagents which are used in the process of extracting metals should be

- Corresponding author: leyla.syzdykova@kaznu.kz 
sufficiently effective, relatively cheap at cost, available, non-toxic, non-degradable, nonvolatile and must not have a strong corrosion effect on the useable device. The selectivity of the reagent used in leaching is important, as alongside with the metal being extracted into the solution, impurities can pass, which makes it necessary to get rid of them.

The most common type of leaching ore is acid leaching using different acid reagents [57]. Thus, hydrochloric acid is an important acid reagent in the processing of polymetallic raw materials, which is associated with the ability of chloride-ion to form complex compound with metal ions [8-9]. In addition, hydrochloric acid unlike sulfuric acid, does not form insoluble compounds with such elements in the ore as barium and calcium. For hydrochloric acidic oxidative leaching, the oxidant sodium hypochlorite is of practical interest, and it is considered as one of the products of its chemical interaction with minerals is metal chlorides [10]. The purpose of this work is to study the kinetics of the leaching mill tailings by sodium hypochlorite solutions in an acidic medium to transfer copper from the solid phase of minerals into the solution and the selection of the optimal leaching mode. The effects of concentration and nature of solvent reagents on copper extraction into the solution were studied.

\section{Experimental}

\subsection{Materials}

Copper mill tailings of Balkhash processing plant was used in this work. Before being leached, the tailing samples were crushed to reach a particle size of -250 mesh. Hydrochloric acid (chemically pure, «Sigma Tech» LLC, Russia) and sodium hypochlorite (technical grade, «Khimkom» LLP, Russia) were used as leaching agents.

\subsection{Leaching procedure}

The process of leaching copper from the tailings weighing $7.5 \mathrm{~g}$ in the presence of hydrochloric acid and sodium hypochlorite was carried out at room temperature using the device of the filtration column (Fig. 1). A glass cylindrical tube was taken as a filtration column. The process consists of the supply of a leaching agent from the vessel (1) using a rubber hose (2) into the filtration column (4), in which a sample of the tailings is placed. The leaching reagent, moving through a layer of the sample gets into the reservoir to collect a productive solution (5), filtered from the tailings solid sample. The feed rate of the leach solution was kept constant in all experiments and was determined by the rate of filtrate accumulation, which averaged $18 \mathrm{ml} / \mathrm{h}$. Two parallel experiments were conducted in each experiment.

Fig. 1. The scheme of the device for filtration leaching of the tailings: 1-reservoir for dissolving reagent; 2-rubber hose; 3-clamp; 4-column filled with sample; 5-reservoir to collect productive solution; 6-tripod.

\subsection{Characterization of solid and liquid samples}

Solid samples of the tailings have been examined using scanning electron microscopy (SEM, Quanta 200, FEI Company, USA) and X-ray diffraction analysis (XRD, Rigaku Smart Lab 3 automatic multifunctional X-ray diffractometer, Japan). Copper ions content in solutions was determined by using atomic absorption spectroscopy, (AAS, Shimadzu AA6200 spectrophotometer, Japan). 


\section{Results and discussion}

To determine the copper content in the tailings the sample was completely decomposed and the metals were transferred into the solution according to the method of [11], the concentration of copper ions in the solution was determined by the AAS method. The content of copper in the solid sample was $0.14 \%$. Using XRD analysis, it was found that the predominant number of peaks belong to quartz $\left(\mathrm{SiO}_{2}\right)$, and characteristic peaks of copper-, zinc -, iron-containing minerals were also found (Fig. 2). This indicates that the content of other minerals is below the detection limit of this method of analysis. On the other hand, it is known that copper tailings contain various copper sulfide minerals; the presence of oxidized copper minerals is also possible, depending on the ore being processed. Fig. 3 shows a micrograph of the surface of the tailings, which depicts that the sample consists of agglomerates of particles of various sizes. At the same time, it is noticed that some particles are distinguishable and have a clear shape. It is assumed that the small fractions of the sample are mostly dissolved due to more developed surface.

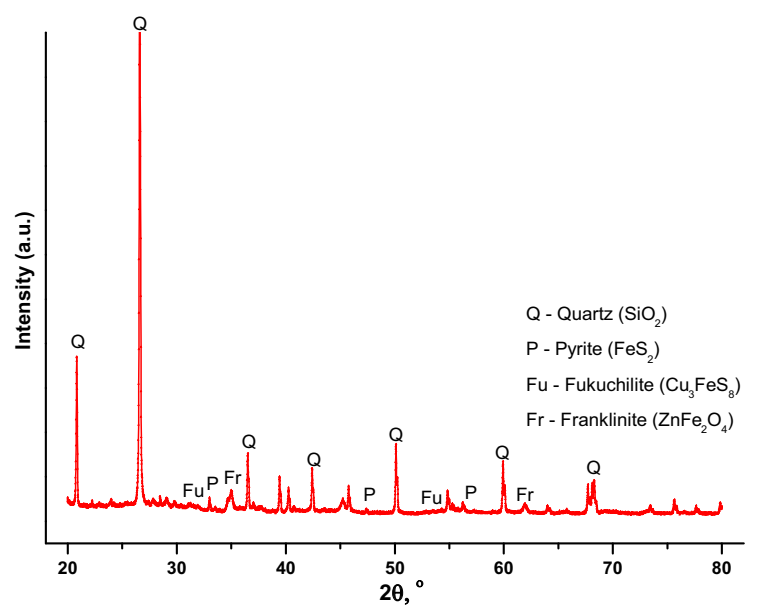

Fig. 2. XRD pattern of the initial sample of the tailings.

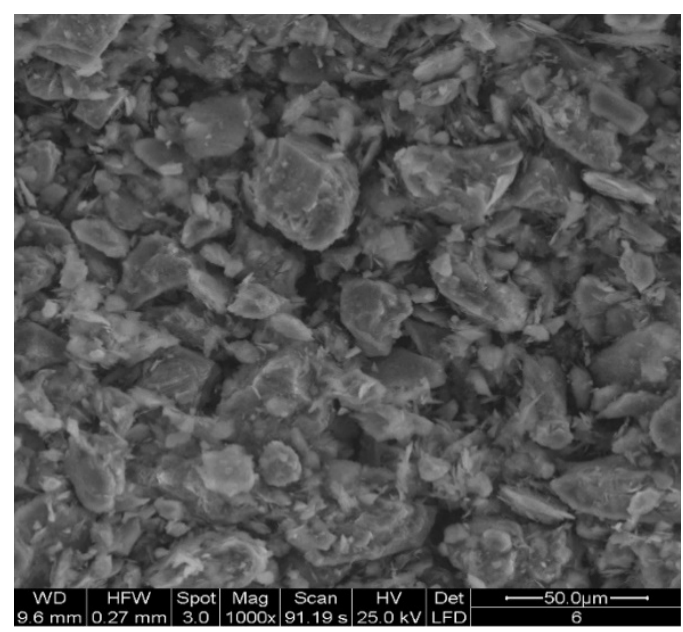

Fig. 3. Microphotography of the initial sample of the tailings. 
The oxidized copper compounds in the tailings are easily dissolved with acidic reagents, and in order to dissolve copper compounds in the sulfide form it is necessary to carry out the leaching process in the presence of an oxidizing reagent. In order to select the optimal concentration of $\mathrm{HCl}$ for leaching the tailings, experiments were first conducted only with this acid (Fig. 4). As can be seen from the Fig. 4, the main amount of copper when adding an acid is dissolved during the 1st hour of the experiment and then the concentration of the extracted copper decreases. This is due to the fact that in the presence of acid, only oxidized copper compounds dissolve in the tailings. The concentration of copper that has passed into a productive solution as a result of leaching of the tailings during the 1 st hour by $0.5 \mathrm{M} \mathrm{HCl}$, $0.25 \mathrm{M} \mathrm{HCl}$ and $0.05 \mathrm{M} \mathrm{HCl}$ was $120.76 \mathrm{mg} / 1,105.25 \mathrm{mg} / \mathrm{l}$ and $77.37 \mathrm{mg} / \mathrm{l}$ respectively. And during the entire experiment $(\mathrm{t}=5 \mathrm{~h})$ the degree of extraction of copper ions from the tailings in the solution reached $21.38 \%$ with the use of $0.5 \mathrm{M} \mathrm{HCl}$. According to the results of the experiment, the concentration of $0.5 \mathrm{M} \mathrm{HCl}$ was chosen as the most effective.

The dissolution of possible oxidized copper compounds (malachite, chrysocolla, tenorite, elites) contained in the tailings in the presence of hydrochloric acid is presented in the following reaction equations:

$$
\begin{aligned}
& \mathrm{CuCO}_{3} \cdot \mathrm{Cu}(\mathrm{OH})_{2}+4 \mathrm{HCl} \rightarrow 2 \mathrm{CuCl}_{2}+\mathrm{CO}_{2} \uparrow+3 \mathrm{H}_{2} \mathrm{O} \\
& \mathrm{CuSiO} \mathrm{O}_{3} \cdot \mathrm{H}_{2} \mathrm{O}+2 \mathrm{HCl} \rightarrow \mathrm{CuCl}_{2}+\mathrm{SiO}_{2}+2 \mathrm{H}_{2} \mathrm{O} \\
& \mathrm{CuO}+2 \mathrm{HCl} \rightarrow \mathrm{CuCl}+\mathrm{H}_{2} \mathrm{O} \\
& \mathrm{Cu}_{5}\left(\mathrm{PO}_{4}\right)_{2}(\mathrm{OH})_{4} \cdot \mathrm{H}_{2} \mathrm{O}+10 \mathrm{HCl} \rightarrow 5 \mathrm{CuCl}_{2}+2 \mathrm{H}_{3} \mathrm{PO}_{4}+5 \mathrm{H}_{2} \mathrm{O}
\end{aligned}
$$

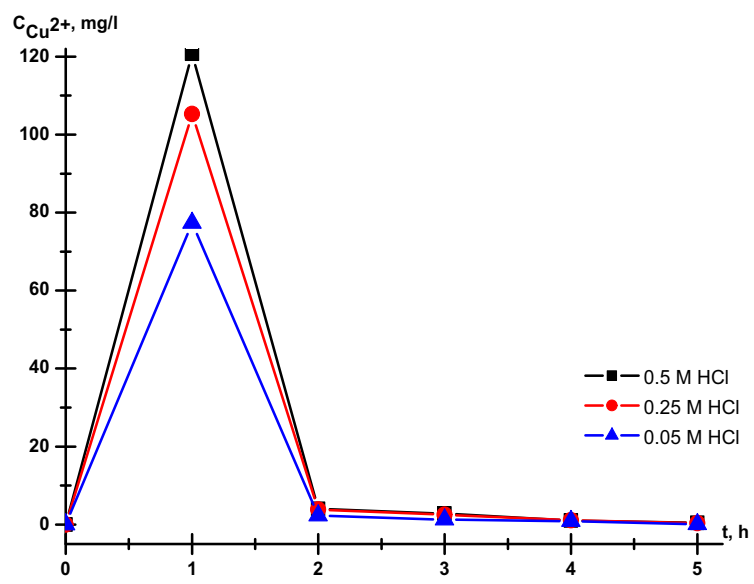

Fig. 4. Dependence of the concentration of copper ions in the solution from leaching duration of the tailings with hydrochloric acid.

For oxidation of sulfur ions $\mathrm{S}^{2-}$ in copper sulfide compounds contained in the tailings to sulfur $\mathrm{S}^{0}$, the oxidizer - sodium hypochlorite was used. The oxidative ability of sodium hypochlorite is higher than that of oxidizing agents such as hydrogen peroxide, sodium nitrite, potassium permanganate, etc. [12]. The following series of experiments was carried out to determine the effective concentration of $\mathrm{NaOCl}$ (Fig. 5). At first, the leaching process was carried out with $0.5 \mathrm{M} \mathrm{HCl}$ for 5 hours, and from the 6th hour $0.025 \mathrm{M}, 0.05 \mathrm{M}$ or 0.1 $\mathrm{M} \mathrm{NaOCl}$ was added to the system. With the addition of the oxidant from the 7 th hour of the experiment, the concentration of copper in the productive solution gradually increased. According to the results of the AAS, as a result of leaching the tailings with solutions of 0.5 $\mathrm{M} \mathrm{HCl}$ with $0.025 \mathrm{M}, 0.05 \mathrm{M}$ and $0.1 \mathrm{M} \mathrm{NaOCl}$ in the 8th hour of the experiment, 0.29 $\mathrm{mg} / \mathrm{l}, 5.18 \mathrm{mg} / \mathrm{l}$ and $20.47 \mathrm{mg} / \mathrm{l}$ of copper were extracted, respectively. Consequently, the copper in the sulfide compounds in the presence of an oxidizer began to pass into the 
solution. During 11 hours of leaching of the tailings with solutions of $0.5 \mathrm{M} \mathrm{HCl}$ and $0.1 \mathrm{M}$ $\mathrm{NaOCl}$, a total of $32.62 \%$ of copper was extracted.

Tailings may contain such copper minerals as covellite, chalcocite, bornite, chalcopyrite; their interaction with hydrochloric acid and sodium hypochlorite can be represented by the following reactions:

$$
\begin{aligned}
& \mathrm{CuS}+2 \mathrm{HCl}+\mathrm{NaOCl} \rightarrow \mathrm{CuCl}_{2}+\mathrm{NaCl}+\mathrm{S}^{o}+\mathrm{H}_{2} \mathrm{O} \\
& \mathrm{Cu}_{2} \mathrm{~S}+4 \mathrm{HCl}+2 \mathrm{NaOCl} \rightarrow 2 \mathrm{CuCl} l_{2}+2 \mathrm{NaCl}+\mathrm{S}^{o}+2 \mathrm{H}_{2} \mathrm{O} \\
& 2 \mathrm{Cu}_{5} \mathrm{FeS}_{4}+26 \mathrm{HCl}+13 \mathrm{NaOCl} \rightarrow 10 \mathrm{CuCl} l_{2}+13 \mathrm{NaCl}+2 \mathrm{FeCl}_{3}+8 \mathrm{~S}^{o}+13 \mathrm{H}_{2} \mathrm{O} \\
& 2 \mathrm{CuFeS}_{2}+10 \mathrm{HCl}+5 \mathrm{NaOCl} \rightarrow 2 \mathrm{CuCl}_{2}+5 \mathrm{NaCl}+2 \mathrm{FeCl}_{3}+4 \mathrm{~S}^{o}+5 \mathrm{H}_{2} \mathrm{O}
\end{aligned}
$$

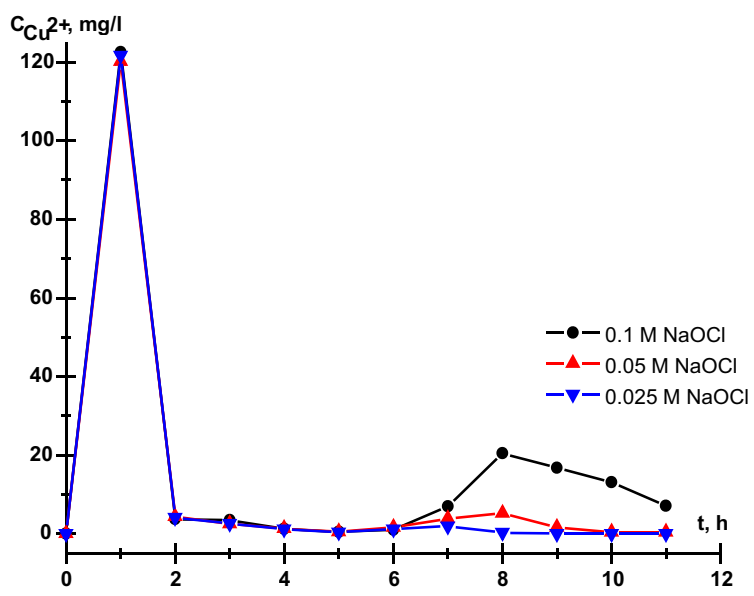

Fig. 5. Dependence of the concentration of copper ions in the solution from leaching duration of the tailings with sodium hypochlorite in an acidic medium $(\mathrm{t}=1 \div 5 \mathrm{~h}-0.5 \mathrm{M} \mathrm{HCl} ; \mathrm{t}=6 \div 11 \mathrm{~h}-\mathrm{NaOCl})$.

After determining the effective concentrations of acidic and oxidizing reagent, the leaching mode was reconsidered. In this regard, the leaching of the tailings was carried out in the system $« 0.5 \mathrm{M} \mathrm{HCl}-0.1 \mathrm{M} \mathrm{NaOCl} »$ for 4 days, alternating daily for 5 hours processing with $\mathrm{HCl}$ and $\mathrm{NaOCl}$ (Fig. 6). On the first day, as a result of leaching of the sample with 0.5 $\mathrm{M} \mathrm{HCl}$ after 1 hour, the concentration of copper in a productive solution reached 120.30 $\mathrm{mg} / \mathrm{l}$. The next day the experiment performed with $\mathrm{HCl}$, was continued with $0.1 \mathrm{M} \mathrm{NaOCl}$, which resulted in the extraction of $7.93 \mathrm{mg} / \mathrm{l}$ of copper, which was much less than the previous experience. On the third day, the sample was treated again with $0.5 \mathrm{M} \mathrm{HCl}$, at which the concentration of copper ions extracted was $12.70 \mathrm{mg} / \mathrm{l}$. It was noted here that when the acid is added to the enrichment sample, saturated with oxidizer, the concentration of copper ions that have passed into a productive solution is much higher than when the oxidizer is added to the acid-rich sample. On the fourth day, the experiment with $0.1 \mathrm{M}$ $\mathrm{NaOCl}$ was similarly repeated. The concentration of copper ions, which turned into a productive solution as a result of sodium hypochlorite leaching, was $6.98 \mathrm{mg} / \mathrm{l}$. The total degree of extraction of copper ions from the tailings into the solution for 4 days of the experiment was $32.86 \%$. According to the results (Fig. 6), leaching time does not have a significant impact on the process, therefore it is possible to increase the efficiency of the leaching mode by changing the sequence of treatment of the sample by reagents - acid and oxidizer. 


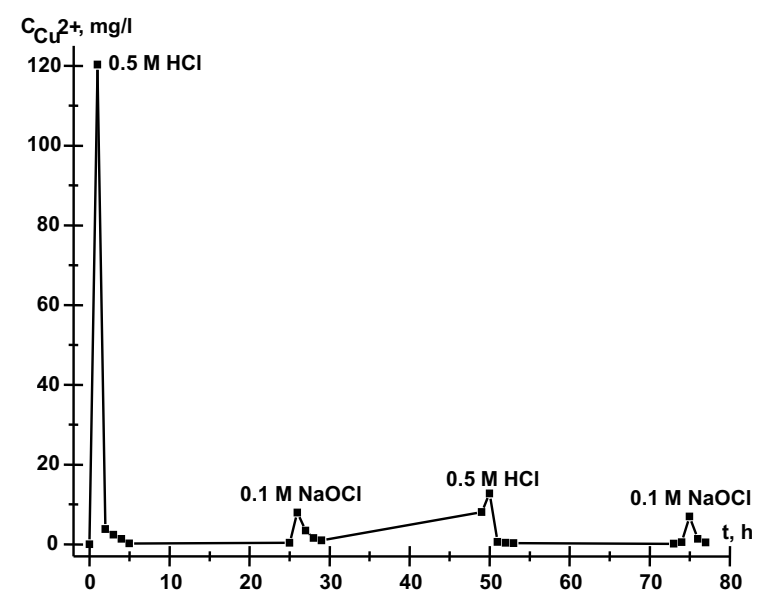

Fig. 6. Dependence of the concentration of copper ions in the solution from leaching duration with the sequential treatment of the tailings with solutions $0.5 \mathrm{M} \mathrm{HCl}$ and $0.1 \mathrm{M} \mathrm{NaOCl}$.

Previous experience has shown the effectiveness of processing the tailings initially by oxidizer $-\mathrm{NaOCl}$, and then by acid reagent $-\mathrm{HCl}$. Therefore, in the subsequent experiment, the tailings were first leached by $0.1 \mathrm{M}$ solution of $\mathrm{NaOCl}$ for 2 hours, then from 3rd hour by $0.5 \mathrm{M} \mathrm{HCl}$ solution for 7 hours (Fig. 7). Based on the results of the AAS, it was determined that when the tailings were leached by $0.1 \mathrm{M} \mathrm{NaOCl}, 0.22 \mathrm{mg} / 1$ of copper was transferred to a productive solution for 2 hours, indicating a practical lack of extraction. This is due to the fact that the oxidative ability of hypochlorite-ion and hypochlorous acid in a neutral medium is much lower than in an acidic medium. Further, when $0.5 \mathrm{M} \mathrm{HCl}$ solution was added at the 3rd hour after $\mathrm{NaOCl}$, it was noted that the concentration of copper that has gone into the productive solution has immediately increased to $487.51 \mathrm{mg} / \mathrm{l}$. In just 9 hours, $87.10 \%$ of copper was extracted. Carrying out leaching of enrichment tailings by this method allows to speed up the process and reduce its duration.

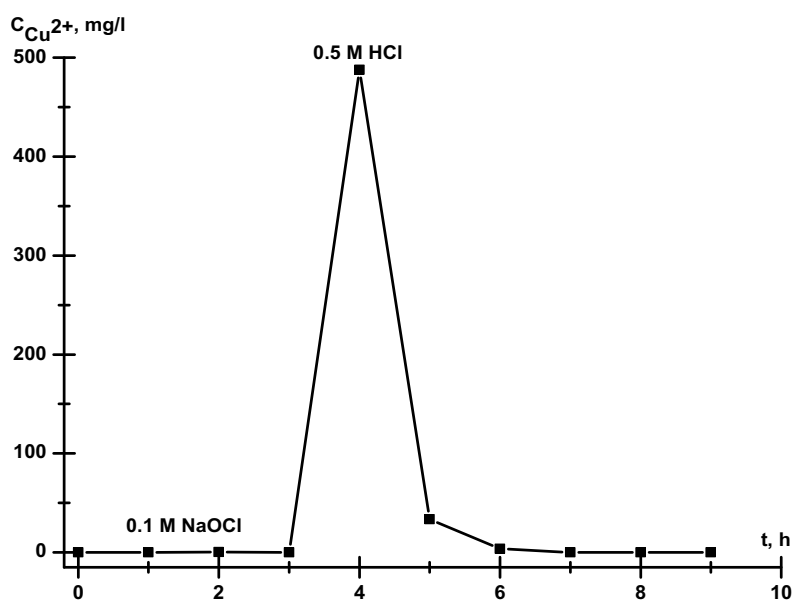

Fig. 7. Dependence of the concentration of copper ions in the solution from leaching duration with the sequential treatment of the tailings firstly with $0.1 \mathrm{M} \mathrm{NaOCl}$, and then $0.5 \mathrm{M} \mathrm{HCl}$. 


\section{Conclusion}

On the basis of the results presented in this study the effectiveness of the use of hydrochloric acid as an acidic reagent and sodium hypochlorite as an oxidizer to leach copper from the tailings of Balkhash processing plant, based on the high oxidative ability of hypochlorite ions in an acidic medium and the complex formation ability of chloride-ions was shown. It has been established that the sequence of alternation of reagents (hydrochloric acid, sodium hypochlorite) when processing the sample in the leaching process, has a significant effect on the extraction of copper from the solid phase into the solution.

\section{References}

1. S.K. Bhargava, M.I. Pownceby, R. Ram, Metals, 6, 5 (2016)

2. O.J. Solis-Marcíal, G.T. Lapidus, Hydromet., 131-132, 120-126 (2013)

3. T. Moyo, J. Petersen, M.J. Nicol, Hydromet., 182, 97-103 (2018)

4. T. Moyo, J. Petersen, M.J. Nicol, Hydromet., 184, 67-74 (2019)

5. M.S. Safarzadeh, J. Li, M.S. Moats, J.D. Miller, Electr. Acta, 78, 133-138 (2012)

6. P.K. Choubey, J. Lee, M. Kim, H-S Kim, Hydromet., 178, 224-230 (2018)

7. V.J. Martínez-Gómez, J.C. Fuentes-Aceituno, R. Pérez-Garibay, Lee Jae-chun, Hydromet., 181, 195-205 (2018)

8. K. Yoo, S. Kim, J. Lee, M. Ito, M. Tsunekawa, N. Hiroyoshi, Miner. Eng., 23(6), 471477 (2010)

9. L. Beiza, V. Quezada, E. Melo, G. Valenzuela, Metals, 9(1) (2019)

10. G. Tiburcio-Munive, M.M. Salazar-Campoy, J.L. Valenzuela-García, O. HernándezNegrete, V. Vázquez-Vázquez, Min., Metall. \& Explor., 37, 1213-1220 (2020)

11. S.Yu. Feinberg. Analysis of non-ferrous metal ores (in Russian), Metallurgizdat, 832 (1953)

12. Kh. Ospanov, K. Smailov, Ye. Nuruly, Sci. of Eur., 2 (44), 27-33 (2019) 